\title{
Near-surface profiles of aerosol number concentration and temperature over the Arctic Ocean
}

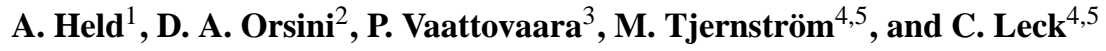 \\ ${ }^{1}$ University of Bayreuth, Bayreuth Center of Ecology and Environmental Research, 95440 Bayreuth, Germany \\ ${ }^{2}$ Leibniz Institute for Tropospheric Research, 04318 Leipzig, Germany \\ ${ }^{3}$ University of Eastern Finland, Department of Applied Physics, 70211 Kuopio, Finland \\ ${ }^{4}$ Stockholm University, Department of Meteorology, 10691 Stockholm, Sweden \\ ${ }^{5}$ Bert Bolin Center for Climate Research, Stockholm University, 10691 Stockholm, Sweden
}

Received: 10 May 2011 - Published in Atmos. Meas. Tech. Discuss.: 23 May 2011

Revised: 8 August 2011 - Accepted: 11 August 2011 - Published: 18 August 2011

\begin{abstract}
Temperature and particle number concentration profiles were measured at small height intervals above open and frozen leads and snow surfaces in the central Arctic. The device used was a gradient pole designed to investigate potential particle sources over the central Arctic Ocean. The collected data were fitted according to basic logarithmic flux-profile relationships to calculate the sensible heat flux and particle deposition velocity. Independent measurements by the eddy covariance technique were conducted at the same location. General agreement was observed between the two methods when logarithmic profiles could be fitted to the gradient pole data. In general, snow surfaces behaved as weak particle sinks with a maximum deposition velocity $v_{\mathrm{d}}=1.3 \mathrm{~mm} \mathrm{~s}^{-1}$ measured with the gradient pole. The lead surface behaved as a weak particle source before freeze-up with an upward flux $F_{\mathrm{c}}=5.7 \times 10^{4}$ particles $\mathrm{m}^{-2} \mathrm{~s}^{-1}$, and as a relatively strong heat source after freeze-up, with an upward maximum sensible heat flux $H=13.1 \mathrm{~W} \mathrm{~m}^{-2}$. Over the frozen lead, however, we were unable to resolve any significant aerosol profiles.
\end{abstract}

\section{Introduction}

The Arctic Summer Cloud Ocean Study (ASCOS) was an international experiment in the summer of 2008 designed to study the processes controlling the surface energy balance in the high Arctic. The Arctic is a unique environment and behaves as its own sensitive system. For example, there were

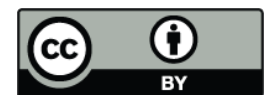

Correspondence to: A. Held (andreas.held@uni-bayreuth.de) significant changes in the ice floes, which appeared to be reacting to ocean currents and a weak diurnal cycle of the Arctic sun. Ironically, many of the changes which appeared subtle impacted the environment dramatically. Total aerosol number concentrations, for example, were as low as $1 \mathrm{~cm}^{-3}$ (Held et al., 2011). A three hundred percent increase in concentration changed that number to $4 \mathrm{~cm}^{-3}$ and was often associated with mesoscale fogs that varied surface temperatures dramatically. The background condition of very low number concentrations was especially interesting for detecting and characterizing local particle sources.

One particular idea of local particle production in the Arctic has been proposed by Leck and Bigg (1999) and followed up by Leck et al. (2002). They hypothesize that bubble bursting in the open waters of the Arctic creates biogenic aerosol particles. The bubbles rise under quiescent waters between the ice floes, and, upon fragmentation at the water surface, generate droplets enriched in the composition of the surface film through which they broke (Blanchard, 1958). Measurements made during the ASCOS campaign confirmed the presence of a population of small $(D<500 \mu \mathrm{m})$ bubbles within the open lead, and an alternative bubble source mechanism driven by the surface heat flux was proposed (Norris et al., 2011).

Bezdek and Carlucci (1974) showed that droplets produced from natural seawater can concentrate, by as much as a factor of 200, bacteria that exist in the surface layer. Recently, enrichment of proteins and bacteria from bubble breaking has also been studied by Aller et al. (2005) and Kuznetsova et al. (2005). In more recent research in the summertime Arctic, transmission electron microscopy photographs of airborne particles were compared with those of particles found in the surface microlayer of the open water

Published by Copernicus Publications on behalf of the European Geosciences Union. 
between ice floes (Bigg et al., 2004; Leck and Bigg, 2005a, b, 2007, 2008, 2010; Bigg and Leck, 2008). The similarity in morphology, physical properties, X-ray spectra and chemical reaction of the numerous aggregates, and of bacteria, viruses and other microorganisms found in both, strongly suggests that the airborne particles were ejected from the water by bursting bubbles. The diffuse electron-transparent material with surfactant properties joining and surrounding the heat resistant and non-hygroscopic colloidal particulates in both the air and water was shown to have properties consistent with the exopolymer secretions (EPS) of microalgae and bacteria in the water. These so-called microgels can be viewed as three-dimensional biopolymer networks containing polysaccharides and monosaccharides, with peptides and proteins attached to the network. The biopolymers are interbridged with divalent ions $\left(\mathrm{Ca}^{2+}\right)$ to give a gel-like consistency (Chin et al., 1998).

Even though open leads have been described as potential sources of atmospheric particles by Scott and Levin (1972) almost $40 \mathrm{yr}$ ago, at the time of this study, the local particle source strength from bubble bursting in the Arctic had not been quantified. The motivation behind this work was to identify this particle source from the open leads by measuring aerosol number concentrations just above the water surface. If the source were strong, an enhanced number of aerosol particles in a layer of air just above the surface might be observed. The film-drop particulate matter generated by bubble bursting might be scavenged by snow or water surfaces while some particles might be mixed upward and act as cloud condensation nuclei.

Vertical particle fluxes have been estimated from fluxprofile relationships and aerosol gradient measurements in previous studies over various surfaces, e.g. over forests (e.g. Wyers and Duyzer, 1997), at the coast (e.g. Ceburnis et al., 2008), and over the open ocean (e.g. Petelski, 2003; Petelski and Piskozub, 2006). Most of these studies investigated aerosol concentration differences at heights up to 20 or $30 \mathrm{~m}$ above the surface. Andreas et al. (1979) report sensible heat fluxes derived from temperature profiles in the lowest $4 \mathrm{~m}$ above Arctic leads in wintertime, and Andreas et al. (1981) investigate flux-profile relationships of condensate droplets about $10 \mu \mathrm{m}$ in diameter during winter. This study focuses on summertime conditions, and on the lowest two meters above the surface, where temperature and aerosol concentration differences are expected to be highest.

\section{Instrument description}

\subsection{Gradient pole method}

Measurements were conducted from a three meter long rod positioned on a tripod (acting as the fulcrum) so that the user could lift an aerosol inlet to fixed heights while remaining at a distance downwind to prevent contamination (Fig. 1). On the user side of this gradient pole, a condensation particle counter (CPC 3010, TSI, St. Paul, MN, USA) along with a vacuum pump and laptop were placed in a small aluminum box for weather protection, and to preserve the small amount of heat produced by the instruments. A 12-volt battery placed outside the box was connected to a 12 VDC/220 VAC converter to supply the power needs of all instruments. The battery also stabilized a wooden board with four nails in the horizontal direction providing hooks for loop-knots which were tied into a nylon cord attached to the end of the rod. The loops allowed for repeatable accuracy $( \pm 1 \mathrm{~cm})$ in positioning the inlet tip at a new height which was necessary to duplicate a height step-series above the ground.

A $30 \mathrm{~cm}$ long diffusion dryer was mounted at the entrance of the inlet to remove water from the aerosol to improve the transmission efficiency. This was especially a concern in high relative humidity conditions where particles might experience a temperature difference in the sampling line and grow by condensation. Following the dryer, the aerosol sample traversed the rod through a straight $2.5 \mathrm{~m}$ long 0.25 inch copper tube. To allow for the vertical movement of the pole, flexible conductive tubing connected the copper tube to the CPC. A critical orifice inside the CPC controlled the aerosol flow to $11 \mathrm{~min}^{-1}$. The total aerosol transit time from inlet to counter was approximately three seconds. The CPC 3010 used in this study for the gradient system had a lower $50 \%$ cutoff diameter at $11 \mathrm{~nm}$ and an upper cutoff diameter of approximately $2.5 \mu \mathrm{m}$. The counts from the CPC were averaged and recorded every second with a laptop.

A thermocouple (Schuricht type 212, sensitivity of $\pm 0.01 \mathrm{~K}$ ) was used to measure the temperature directly next to the inlet tip. The thermocouple consisted of two very thin type-k wires tied together for rapid response. The analog signal from the temperature probe was sent via a sheathed cable to an analog/digital converter and sampled at approximately $10 \mathrm{~Hz}$ to record an average every $0.5 \mathrm{~s}$.

The height of each measurement position, i.e. the distance from the inlet tip to the surface, was measured by an ultrasonic height sensor (Pepperl+Fuchs, UC2000-30GM) which was placed on the rod at a location slightly behind the aerosol inlet. An additional weight was attached to the bottom of the height sensor so that the height sensor would always point vertically towards the ground as the gradient pole was raised and lowered. Using basic geometry, the height of the inlet tip was calculated from the height of the sensor and its position on the pole. The ultrasonic height readings were recorded every $0.5 \mathrm{~s}$. Since the operating principle of the height sensor is to detect its own reflected ultrasound signal, a flat board placed on the ground beneath the sensor helped to decrease the noise over rough snow surfaces. This gave us a height sensitivity of $\pm 0.25 \mathrm{~cm}$, better than that of the height positioning itself. All gradient measurements took place with the gradient pole deployed "over lead" or "over snow" and were performed with the pole pointed into the wind to avoid contamination. 


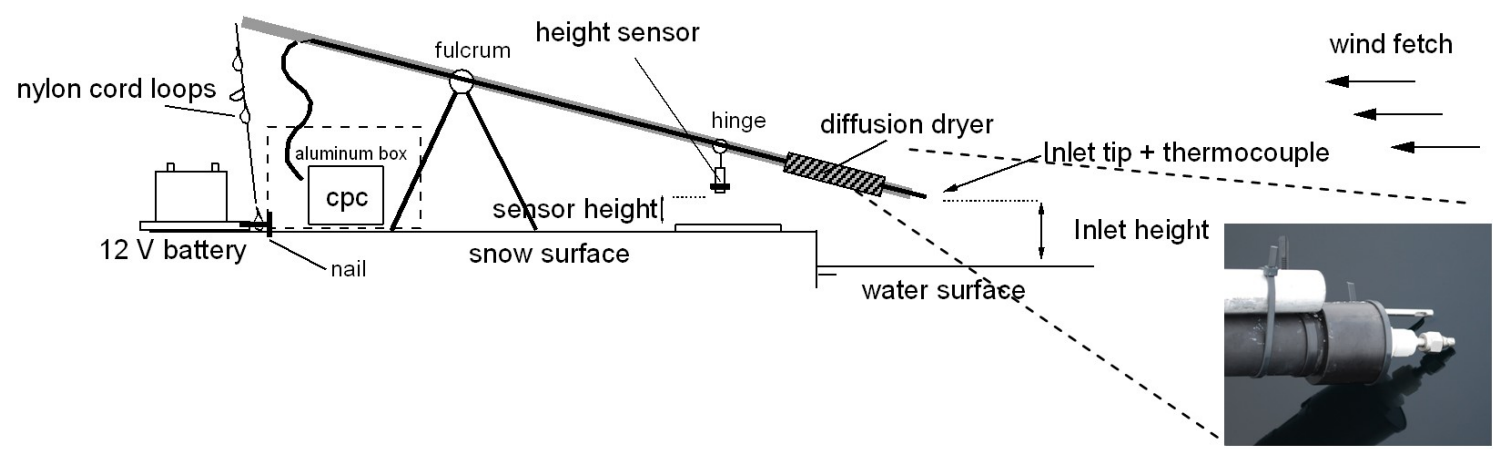

Fig. 1. Schematic of the gradient pole to measure particle number concentration and temperature profiles above snow and water surfaces. The pole is lifted up and down on the user side so that the inlet can return to various fixed heights above the surface.

\subsection{Eddy covariance method}

An eddy covariance (EC) system was set up on the edge of the lead approximately $300 \mathrm{~m}$ from the gradient pole, directly measuring turbulent fluxes of sensible and latent heat and aerosol number concentrations at a height of $2.5 \mathrm{~m}$ (Held et al., 2011). The system consisted of a Gill R3 sonic anemometer (Gill, Lymington, UK) for three-dimensional wind measurements, a Licor LI-7500 open path analyzer (Licor, Lincoln, NE, USA) for carbon dioxide $\left(\mathrm{CO}_{2}\right)$ and water $\left(\mathrm{H}_{2} \mathrm{O}\right)$ vapor concentration measurements, and a condensation particle counter CPC 3760A (TSI, St. Paul, MN, USA) for particle number measurements. The CPC 3760A has a nominal lower cutoff diameter of $11 \mathrm{~nm}$ and an upper cutoff diameter of approximately $3 \mu \mathrm{m}$.

Turbulent fluxes were calculated according to standard eddy covariance procedures in 30 min averaging periods after rotation of the turbulent winds into a streamline coordinate system using the planar fit method (Wilczak et al., 2001) and linear detrending. Due to the traveling time of the aerosol sample from the sampling point through the inlet tubing to the particle counter, and the traveling time in the particle counter, a constant time lag of $2.6 \mathrm{~s}$ was applied to synchronize the wind and the aerosol time series. The sampling line degraded the response time of the particle counter with regard to ambient concentration changes. It is important to bear in mind that this eddy covariance setup cannot resolve $10 \mathrm{~Hz}$ aerosol number concentration fluctuations. With an estimated response time of $1.4 \mathrm{~s}$ and typical wind speeds of less than $4 \mathrm{~m} \mathrm{~s}^{-1}$, we found the underestimation of the aerosol fluxes due to fluctuation dampening to be less than $20 \%$ for this study using the approach by Horst (1997). No additional corrections were applied. After calculating the turbulent aerosol number fluxes by eddy covariance, the deposition velocity $v_{\mathrm{d}}$ was derived by normalizing the flux $F_{\mathrm{c}}$ with the number concentration $c$, i.e. $v_{\mathrm{d}}=-F_{\mathrm{c}} c^{-1}$. The negative sign is convention to obtain positive deposition velocities in case of aerosol deposition fluxes directed towards the surface. The eddy covariance results given in this work are for the $30 \mathrm{~min}$ averaging period encompassing the sampling time of the gradient pole, or the median value of the eddy covariance averaging periods encompassing the gradient pole sampling period.

\section{Sampling methodology}

The gradient pole was deployed for eight days within the pack ice area (24 August to 1 September 2008) during the ASCOS expedition when the icebreaker Oden was moored to an ice floe in the Arctic Ocean. The full drift lasted from 12 August to 1 September 2008. During these 21 days the ice floe drifted slowly west- and southward about the coordinates $2^{\circ}-10^{\circ} \mathrm{W}$ and $87^{\circ}-87.5^{\circ} \mathrm{N}$. Upon arrival, the ice surface was composed of loose granular snow and covered by a large number of melt ponds. The larger ice floes were separated by open ocean leads. Ice algae were often visible below the ice. Our initial goal with the gradient pole was to detect particle number concentrations directly over the water surface of the lead.

The eight day period when the gradient pole was deployed was marked by the initial transition into the autumn freeze-up with the skinning over of water surfaces. On 27 August, the open lead did not recover from its diurnal freeze cycle and remained frozen thereafter. Snow fall covered melt ponds and increased surface reflectivity. High relative humidity and low aerosol concentrations also led to substantial formation of rime. In order to avoid contamination, the gradient pole was deployed keeping the inlet tip upwind. In addition, measurements were only performed when the wind came from a direction absent of any human activity, including the position 


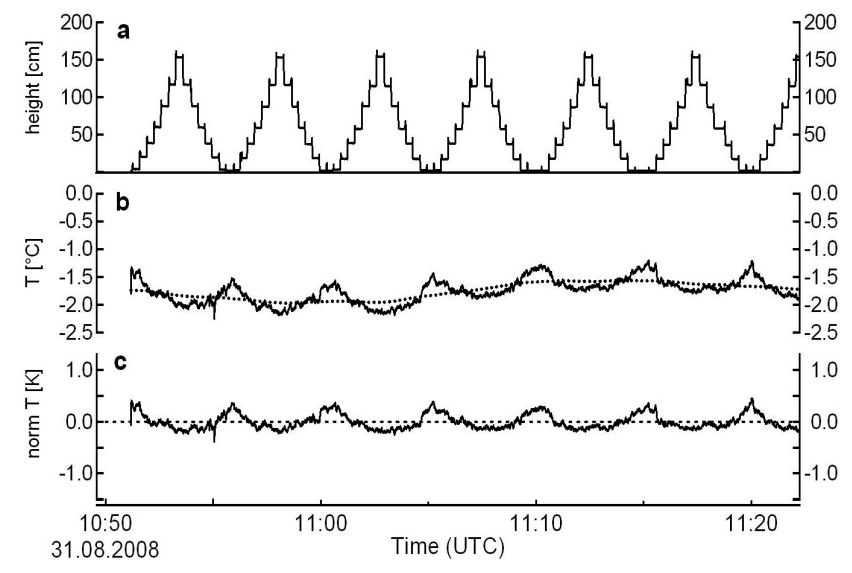

Fig. 2. Temperature data acquired with the gradient pole on $31 \mathrm{Au}-$ gust over the frozen lead: (a) measurement height [cm], (b) temperature $\left[{ }^{\circ} \mathrm{C}\right]$, (c) normalized temperature $[\mathrm{K}]$.

of the ship. The lead itself was located approximately $3 \mathrm{~km}$ away from the ship. During the measurement period, the total particle number concentrations measured with the CPC were all below $100 \mathrm{~cm}^{-3}$, and decreased progressively to values below $10 \mathrm{~cm}^{-3}$.

\section{Data analysis}

\subsection{Temperature profiles}

It was necessary to develop a standard method to consistently analyze all raw data collected by the gradient pole. The analysis procedure is presented here with examples for temperature and concentration data. Figure $2 \mathrm{a}$ and $\mathrm{b}$ shows raw height and temperature profiles collected over the Arctic pack ice on 31 August 2008. The triangular patterns in Fig. 2a show a series of up and down height traces of the inlet. The inlet was held at each step for approximately $20 \mathrm{~s}$ before changing to the next height. The small spikes seen on the height steps are due to overshoot of the pole.

To consider the measured temperature changes due to variations in the inlet height only, it was necessary to remove the slower temperature trends. For each measurement run, a rolling boxed-median of 1500 data points $(\sim 15 \mathrm{~min})$ shown as a dotted line in Fig. 2b was subtracted from the raw data. By subtracting the baseline from the raw data, the normalized temperature trace centered at $0^{\circ} \mathrm{C}$ is produced (Fig. 2c).

With the slower ambient temperature trend removed, the normalized temperature data plotted directly against the inlet height revealed groups of temperature points at each level (Fig. 3a). Each of these groups of data points was averaged and the means are plotted in Fig. 3b with the respective standard deviations as the error bars. Since the error bars for some data points overlap with others, we first determined whether the mean data points are significantly different from

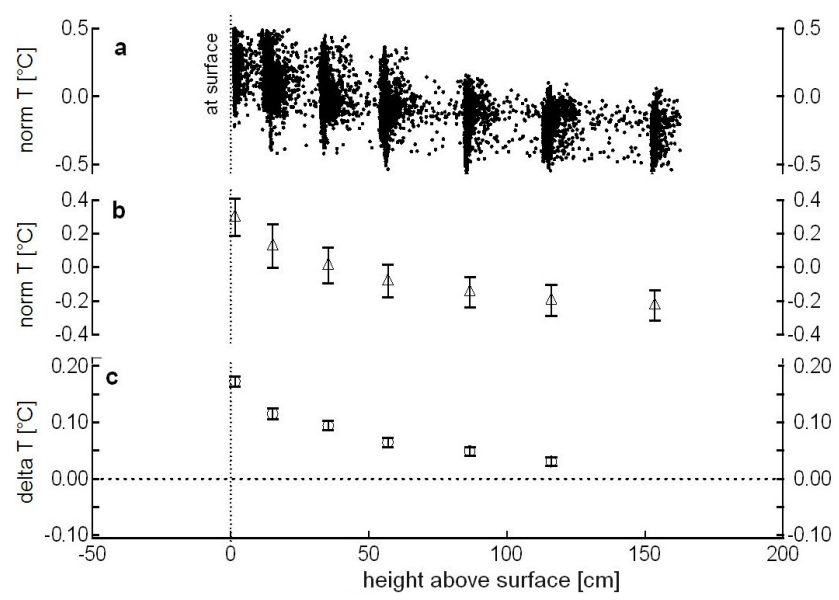

Fig. 3. Significance of temperature gradient in profile data: (a) individual data points of normalized temperature, (b) normalized temperature averaged at each height with the standard deviations as the error bars, and (c) the difference between adjacent means from left to right with \pm twice the standard errors as the error bars.

one another. If we take the difference between adjacent pairs of mean temperatures from left to right, we produce the data points in Fig. 3c. The error bars in Fig. 3c are derived from the standard error SE of the difference between two adjacent means,

$\mathrm{SE}=\sqrt{\frac{\sigma_{1}^{2}}{\left(N_{1}-1\right)}+\frac{\sigma_{2}^{2}}{\left(N_{2}-1\right)}}$,

where $\sigma_{1}$ and $\sigma_{2}$ are the respective standard deviations, and $N_{1}$ and $N_{2}$ are the number of measured data points. In common practice, the $95 \%$ confidence interval is obtained by taking twice the standard error (Lanzante, 2005), shown as error bars in Fig. 3c. If twice the standard error is greater than the difference, then the error bar will cross zero and the two mean data points are considered "not significantly different".

In the case shown in Fig. 3c, the error bars for all adjacent mean pairs do not cross zero. For the sake of completeness, we extend the analysis one step further by applying an independent two-tailed T-test to each pair of mean values. Closely related, the t-value is the difference between two means divided by the standard error. Table 1 shows the $\mathrm{t}$-values and the probabilities to not reject the null hypothesis (that two points are statistically the same) for a common, yet arbitrary significance level $\alpha=0.05$. The null hypothesis is rejected for all data pairs, and therefore we conclude that the adjacent data points are significantly different, despite the overlapping standard deviations.

For the purpose of this study, a profile is considered valid if the following two criteria are met: (1) a minimum of four adjacent data points (three adjacent pairs) must be significantly different from each other, and (2) the difference between adjacent data points is either positive for all pairs, or 
Table 1. T-test results for adjacent means of the temperature profile on 31 August.

\begin{tabular}{lllllll}
\hline levels & $\begin{array}{l}\text { N data } \\
\text { points } \\
\text { per level }\end{array}$ & $\begin{array}{l}\text { difference } \\
\text { between } \\
\text { means }\end{array}$ & $\begin{array}{l}\text { standard } \\
\text { error } \\
\left(\times 10^{-3}\right)\end{array}$ & t-statistic & $\begin{array}{l}\text { probability } \\
(\alpha=0.05)\end{array}$ & $\begin{array}{l}\text { null } \\
\text { hypothesis }\end{array}$ \\
\hline $1 / 2$ & $2971 / 2130$ & 0.173 & 4.37 & 39.4 & $1 \mathrm{e}-290$ & reject \\
$2 / 3$ & $2130 / 2091$ & 0.116 & 4.62 & 29.9 & $1 \mathrm{e}-128$ & reject \\
$3 / 4$ & $2091 / 2124$ & 0.094 & 4.14 & 22.7 & $1 \mathrm{e}-108$ & reject \\
$4 / 5$ & $2124 / 2068$ & 0.065 & 3.92 & 16.6 & $1 \mathrm{e}-59$ & reject \\
$5 / 6$ & $2068 / 2101$ & 0.049 & 3.69 & 13.2 & $1 \mathrm{e}-35$ & reject \\
$6 / 7$ & $2101 / 1485$ & 0.031 & 3.86 & 7.9 & $1 \mathrm{e}-15$ & reject \\
\hline
\end{tabular}

negative for all pairs. It should be stressed that a profile measurement may still be perfectly valid without satisfying these criteria. In particular, criterion (1) is simply an indication that the differences between two heights could be resolved by our measurements. Under neutral conditions or for closer spaced measurement levels, this criterion will eventually not be met.

\subsection{Aerosol concentration profiles}

In Fig. 4, particle number concentration data collected with the gradient pole over the Arctic pack ice on 28 August are presented. We choose this example because it illustrates a weak gradient that was resolved despite the large variability in the particle counts. For consistency, we take the same data approach as for the temperature case. Fig. 4a displays the height profiles, which appear less uniform than in the temperature case discussed above. The irregularity in the profiles was present in the beginning stages of the experimental runs due to lack of practice with raising and lowering the gradient pole and struggling with initial adjustments of the setup in the cold conditions. As can be seen in the latter part of the measurement period, we also tried faster scanning of the profiles, but the results provided poor averaging statistics.

Figure $4 \mathrm{~b}$ displays the particle number concentration recorded every second. Despite the natural short-term fluctuations which are on the order of 10 particles $\mathrm{cm}^{-3}$, a weak gradient can be discerned which tracks the changes in height. As previously done for the temperature case, a median baseline is subtracted from the raw data producing the normalized data in Fig. 4c.

The profile extracted from the normalized data is shown in Fig. 5. Because of the data scatter due to the non-uniform height levels, we show both the time and height standard deviations in the groups of points which are averaged. Using the standard error method, the differences between the four data points that are resolved nearest to the surface in Fig. $5 \mathrm{c}$ are consistent in their sign of gradient, and thus confirm the existence of a valid gradient. The T-test results (Table 2) show that the null hypothesis is rejected for all data pairs ex-
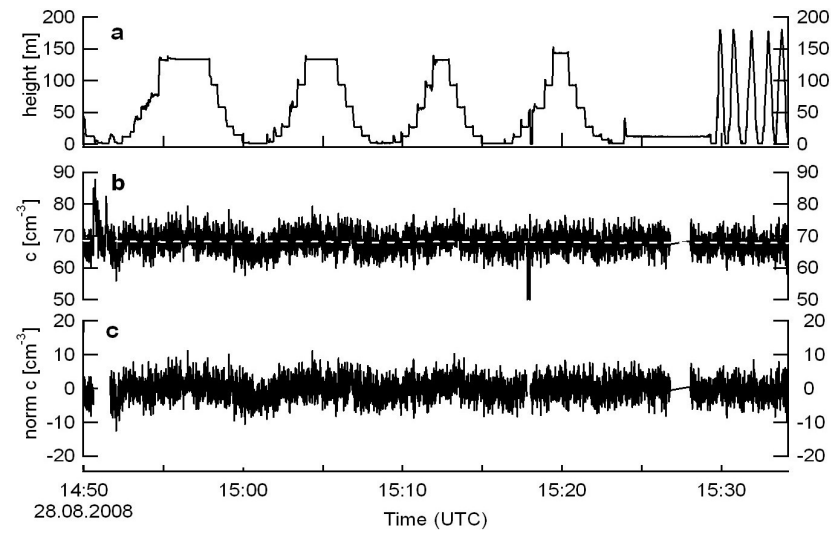

Fig. 4. Particle concentration data acquired with the gradient pole on 28 August over the snow surface: (a) measurement height [cm], (b) particle concentration $\left[\mathrm{cm}^{-3}\right]$, (c) normalized particle concentration $\left[\mathrm{cm}^{-3}\right]$. A total of 7 scans began at 14:20 (initial data not shown), with an average sampling time per height level=20 s. Average data points per height level $=1200$.

cept the pair of data points 4 and 5. This indicates that adjacent data points (except data points 4 and 5) are significantly different.

\subsection{Flux-profile relationships}

In a layer near the surface, turbulent fluxes are considered to be constant with height. Thus, vertical fluxes and gradients may be related using Monin-Obukhov similarity theory in this so-called constant flux layer (cf. Kaimal and Finnigan, 1994; Foken, 2008). For the turbulent fluxes of momentum and sensible heat, $F_{\mathrm{m}}$ and $F_{\mathrm{h}}$, we obtain

$$
\begin{aligned}
& F_{\mathrm{m}}=\overline{u^{\prime} w^{\prime}}=-K_{\mathrm{m}} \frac{\partial U}{\partial z}, \\
& F_{\mathrm{h}}=\overline{w^{\prime} T^{\prime}}=-K_{\mathrm{h}} \frac{\partial T}{\partial z},
\end{aligned}
$$

where $\overline{u^{\prime} w^{\prime}}$ is the covariance of horizontal and vertical wind speed, $\overline{w^{\prime} T^{\prime}}$ is the covariance of vertical wind speed and 
Table 2. T-test results for adjacent means of the aerosol concentration profile on 28 August.

\begin{tabular}{lllllll}
\hline levels & $\begin{array}{l}\text { N data } \\
\text { points } \\
\text { per level }\end{array}$ & $\begin{array}{l}\text { difference } \\
\text { between } \\
\text { means }\end{array}$ & $\begin{array}{l}\text { standard } \\
\text { error } \\
\left({\left.\mathrm{x} 10^{-3}\right)}^{-3}\right.\end{array}$ & t-statistic & $\begin{array}{l}\text { probability } \\
(\alpha=0.05)\end{array}$ & $\begin{array}{l}\text { null } \\
\text { hypothesis }\end{array}$ \\
\hline $1 / 2$ & $1220 / 821$ & -1.0115 & 0.137 & -10.7 & $1 \mathrm{e}-26$ & reject \\
$2 / 3$ & $821 / 537$ & -0.4824 & 0.164 & -4.03 & $1 \mathrm{e}-05$ & reject \\
$3 / 4$ & $537 / 939$ & -0.4063 & 0.165 & -3.52 & $3 \mathrm{e}-04$ & reject \\
$4 / 5$ & $939 / 435$ & -0.0570 & 0.172 & -0.50 & 0.620 & do not reject \\
$5 / 6$ & $435 / 1110$ & -0.3666 & 0.169 & -3.34 & 0.001 & reject \\
\hline
\end{tabular}

Average sample time per level $=844 \mathrm{~s}$ or $14.1 \mathrm{~min}$.

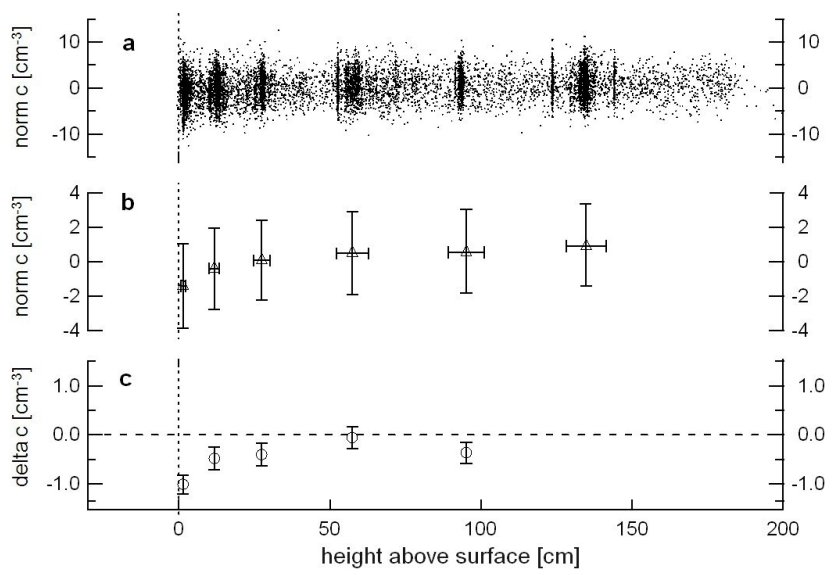

Fig. 5. Significance of particle number gradient in profile data: (a) individual data points of normalized particle number concentration, (b) normalized particle number concentration averaged at each height with the standard deviations as the error bars, and (c) the difference between adjacent means from left to right with \pm twice the standard errors as the error bars.

temperature, $U$ is the wind speed [ $\left.\mathrm{m} \mathrm{s}^{-1}\right], T$ is the temperature $[\mathrm{K}]$, and $z$ is the measurement height $[\mathrm{m}]$.

$K$ is the eddy diffusivity,

$K_{\mathrm{m}, \mathrm{h}}=\frac{k z u_{*}}{\phi_{\mathrm{m}, \mathrm{h}}(z / L)}$,

where $k$ is the von Karman constant $(=0.40), u_{*}$ is the friction velocity $\left[\mathrm{m} \mathrm{s}^{-1}\right]$, and subscripts $\mathrm{m}$ and $\mathrm{h}$ refer to momentum and sensible heat, respectively. $\phi_{\mathrm{m}, \mathrm{h}}(z / L)$ are the corresponding stability correction functions

In the literature, values between 1.0 and 1.39 are reported for the ratio $K_{\mathrm{h}} / K_{\mathrm{m}}$ (which is the inverse of the turbulent Prandtl number, e.g. Foken, 2008). Values larger than unity imply that heat transport is more effective than momentum transport. For reasons of simplicity, we will use a value of unity, thus $K_{\mathrm{h}}=K_{\mathrm{m}}$.



Fig. 6. Probability density function of the stability parameter $z / L$, based on the whole ASCOS measurement period near the lead.

The stability functions for the fluxes of momentum and sensible heat, $\phi_{\mathrm{m}}$ and $\phi_{\mathrm{h}}$, depend only on the dimensionless height, $z / L$, where $L$ is the Obukhov length,

$L=-\frac{u_{*}^{3}}{k \frac{g}{T_{0}} \overline{w^{\prime} T^{\prime}}}$,

$g$ is the gravitational acceleration $\left(=9.81 \mathrm{~m} \mathrm{~s}^{-2}\right)$, and $T_{0}$ is a reference temperature.

The stability correction functions are determined empirically, and many different formulations for the functional shape of $\phi$ have been suggested in the literature (e.g. Dyer, 1974; Businger, 1988). For neutral stratification, i.e. $z / L=0$, the stability correction functions are unity by definition, $\phi(0)=1$. Based on the eddy covariance observations at the open lead during ASCOS, the magnitude of the dimensionless height, $z / L$, was inside the interval \pm 0.04 for about $70 \%$ of the total time of the deployment (Fig. 6). Therefore, we proceed to ignore the stability correction functions, thereby accepting a $<10 \%$ error. 
Using these simplifications and integrating Eq. (3) between the two heights $z_{1}$ and $z_{2}$, we arrive at

$$
T_{2}-T_{1}=-\frac{F_{\mathrm{h}}}{u_{*} k} \ln \left(\frac{z_{2}}{z_{1}}\right) .
$$

The sensible heat flux indicates a positive (upward) flux of sensible heat when $T_{2}<T_{1}$, and vice versa. Strictly speaking, Eq. (6) is only true for potential temperature. In this study performed in the lowest $2 \mathrm{~m}$ of the boundary layer at sea level, we used the differences of actual air temperature at two heights as a good approximation of the differences of potential temperature at these two heights. It should be kept in mind that the difference between actual and potential temperature increases with height, thus introducing a small bias to the temperature difference. For a pressure drop of roughly $0.143 \mathrm{hPa} \mathrm{m}^{-1}$, a typical temperature of $273 \mathrm{~K}$, and a typical pressure of $1013 \mathrm{hPa}$ we obtain a change in temperature of $0.022 \mathrm{~K}$ between the surface and a height of $2 \mathrm{~m}$.

We can also derive the relationship of the particle number concentration profile and the particle number flux,

$c_{2}-c_{1}=-\frac{F_{\mathrm{c}}}{u_{*} k} \ln \left(\frac{z_{2}}{z_{1}}\right)$,

where $c_{1}$ and $c_{2}$ are the particle number concentrations in the measurement heights $z_{1}$ and $z_{2}$, and $F_{\mathrm{c}}$ is the particle number flux. Again, we assume the turbulent eddy diffusivity for particle number, $K_{\mathrm{c}}=K_{\mathrm{m}}$, and the stability correction function for the particle number flux, $\phi_{\mathrm{c}}(0)=1$. It should be emphasized that the theoretical assumptions underlying Eq. (7), i.e. Monin-Obukhov similiarity theory, have not been validated for atmospheric aerosols. However, our aerosol data show consistency with the logarithmic profile of Eq. (7), whereas a widely used equation for the theoretical form of aerosol concentration above a surface source (e.g. Fairall et al., 2009),

$c_{z}=c_{h}\left(\frac{z}{h}\right)^{\frac{v_{\mathrm{g}}}{u_{*} k}}$,

with $c_{z}$ being the aerosol concentration at height $z, c_{h}$ being a reference concentration at an arbitrary height $h$, and $v_{\mathrm{g}}$ the gravitational settling velocity, cannot explain the observed concentration differences. We note that Eq. (8) depends strongly on $v_{\mathrm{g}}$; during ASCOS, the portion of the aerosol spectrum sampled by the CPC was dominated by sub-100 nm particles. This is consistent with previous observations of a distinct Aitken mode in the Arctic aerosol (e.g. Covert et al., 1996; Leck and Bigg, 2005b). For such small particles, $v_{\mathrm{g}}$ is negligibly small, and turbulent particle fluxes will behave similar to other scalar fluxes. Andreas et al. (2010) use the exponent of Eq. (8), $v_{\mathrm{g}} / u_{*} k$, to identify the dominant process, gravitational settling or turbulent mixing. For typical $u_{*}=0.1 \mathrm{~m} \mathrm{~s}^{-1}$ and a particle diameter of $100 \mathrm{~nm}$, we find an exponent of $\sim 3 \times 10^{-5}$, while for a particle diameter of $5 \mu \mathrm{m}$, the exponent is roughly 0.03 . Thus, for our conditions, turbulent mixing clearly dominates over gravitational settling, which is not the case for supermicron particles.

Equations (6) and (7) allow us to calculate the sensible heat flux, $F_{\mathrm{h}}$, and the particle number flux, $F_{\mathrm{c}}$, from gradients of temperature $T$ and particle number concentration $c$, provided that the value of the friction velocity, $u_{*}$, is known. In the present case, we have independent information of $u_{*}$, and also of sensible heat and aerosol flux, from simultaneous eddy covariance flux measurements.

If we presume that our temperature data behave according to Eq. (6), then we can plot the temperature differences $\left(T_{2}-T_{1}\right)$ against the logarithmic height ratio $\ln \left(z_{2} / z_{1}\right)$ and produce a linear plot with a slope that equals $-F_{\mathrm{h}}\left(u_{*} k\right)^{-1}$. If we obtain $u_{*}$ from the eddy covariance data, we can solve for the heat flux $F_{\mathrm{h}}$ from the slope of a linear regression. Likewise, the same can be done for the particle concentration data using Eq. (7), solving for $F_{\mathrm{c}}$. We acknowledge ongoing discussions about the appropriate value of the von Karman constant $k$ in the case of particle concentration (Petelski and Piskozub, 2006, 2007; Andreas, 2007). However, our data are too limited to contribute to this discussion, and we proceed with a value of $k=0.40$.

It should be pointed out that the slope of the linear regression for Eqs. (6) and (7), and thus the flux estimate $F_{\mathrm{h}}$ and $F_{\mathrm{c}}$, is identical to the slope derived from the more standard approach of analyzing flux-profile relationships, i.e. fitting a least-squares relation between $\ln (z)$ and $T$ or $c$, respectively.

\subsection{Flux estimates from profile measurements}

We will now illustrate two examples using the above equations to solve for the sensible heat flux $F_{\mathrm{h}}$ and the particle number flux $F_{\mathrm{c}}$. For the case of $F_{\mathrm{h}}$, we take profile data from a period on 31 August (31/08a) and plot the temperature differences $\left(T_{2}-T_{1}\right)$ between the height levels on the vertical axis and $\ln \left(z_{2} / z_{1}\right)$ on the horizontal axis to produce Fig. 7a. In this particular case on 31 August, the gradient pole was used to measure the temperature at seven height levels above the frozen lead. Using all possible combinations of temperature differences between seven height levels yields $6+5+4+3+2+1$ permutations of $\left(T_{2}-T_{1}\right)$ or 21 data points.

As mentioned previously, the data points should fall on a straight line with a slope that equals $-F_{\mathrm{h}}\left(u_{*} k\right)^{-1}$. In Fig. 7a, however, two diverging trends emerge from opposite corners of the figure. The six data points that originate from the lower right-hand corner represent temperature differences with the lowest height level. The data points which appear to follow the second trend in the top left-hand corner represent temperature differences between all other height levels. One might think that the temperature measurement closest to the ground were faulty, since had it not been present, all data would fall along the same line. However, we have no additional 

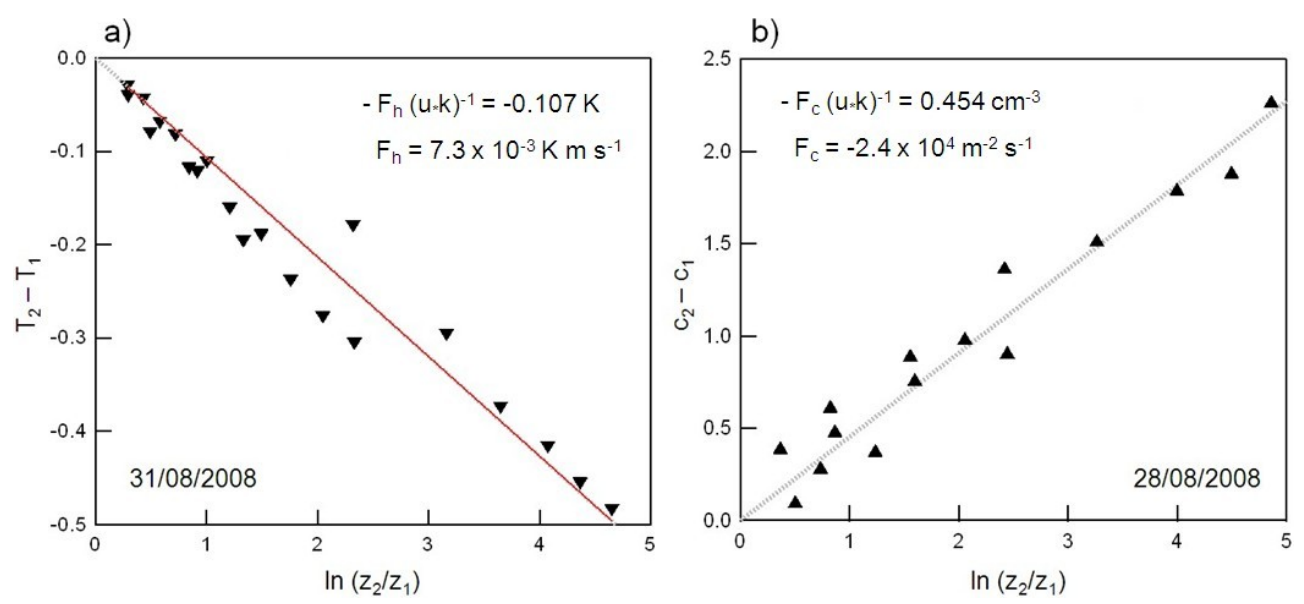

Fig. 7. Estimation of (a) the sensible heat flux $F_{\mathrm{h}}$ on 31 August and (b) the particle number flux $F_{\mathrm{c}}$ on 28 August from a linear regression of the temperature and particle concentration profiles according to Eqs. (6) and (7), respectively.

evidence for this, and by keeping all data intact in the figure, we gain insight into the variability of the data with respect to the logarithmic behavior.

The surface layer similarity theory, from which this behavior arises, is strictly valid only for measurement heights much larger than the roughness length $z_{0}$. Values of $z_{0}$ over summer sea ice are given in the literature as typically $10^{-5}$ to $10^{-2} \mathrm{~m}$ (Held et al., 2011; Persson et al., 2002; Tjernström, 2005). Thus, the presented measurements should be valid down to a few centimeters above the surface.

A linear regression fit to the data in Fig. 7a yields a slope of -0.107 with a coefficient of determination, $R^{2}=0.98$. Setting the slope equal to $-F_{\mathrm{h}}\left(u_{*} k\right)^{-1}$ yields a kinematic sensible heat flux $F_{\mathrm{h}}=7.3 \times 10^{-3} \mathrm{~K} \mathrm{~m} \mathrm{~s}^{-1}$. This is a positive value, indicating that the heat flux is upward and that the surface behaves as a heat source. We obtain the sensible heat flux $H$ in dynamic units $\left[\mathrm{W} \mathrm{m}^{-2}\right]$ by multiplying the sensible heat flux in kinematic units $\left[\mathrm{K} \mathrm{m} \mathrm{s}^{-1}\right]$ by the product of the air density, $\rho_{\text {air }}=1.225 \mathrm{~kg} \mathrm{~m}^{-3}$, and the specific heat of air, $c_{\mathrm{p}}=1004 \mathrm{~J} \mathrm{~kg}^{-1} \mathrm{~K}^{-1}$. In this case we obtain $H=8.9 \mathrm{~W} \mathrm{~m}^{-2}$. This is in good agreement with the sensible heat flux obtained from eddy covariance measurements, $H=6.7 \mathrm{~W} \mathrm{~m}^{-2}$.

We now demonstrate the same approach for particle number data measured on 28 August over the snow surface. Figure $7 \mathrm{~b}$ shows the particle number concentration differences $\left(c_{2}-c_{1}\right)$ plotted against the respective height ratios $\ln \left(z_{2} / z_{1}\right)$. The regression line has a slope of +0.454 with $R^{2}=0.98$. When set equal to $-F_{\mathrm{c}}\left(u_{*} k\right)^{-1}$, we obtain a particle number flux of $-2.4 \times 10^{4} \mathrm{~m}^{-2} \mathrm{~s}^{-1}$. The negative value indicates particle deposition. The particle number concentration decreased towards the surface also indicating an aerosol sink. Finally, we obtain the particle deposition velocity by normalizing $F_{\mathrm{c}}$ with the ambient particle number concentration $c, v_{\mathrm{d}}=F_{\mathrm{c}} c^{-1}$, here $v_{\mathrm{d}}=0.38 \mathrm{~mm} \mathrm{~s}^{-1}$.
To provide clarity to the outlined procedures, we briefly recap what has been done. First, the raw temperature and aerosol concentration data measured with the gradient pole was normalized to create an average data set as a function of height. Second, a linear method of standard errors was applied to the averaged data for each date to determine if an observed gradient was significant. Third, the same averaged data were plotted for each date according to a theoretical flux-profile relationship to extract a slope and $R^{2}$ value from a linear regression. In contrast to the standard error method, the coefficients of determination, $R^{2}$, signify how well the data conform to the logarithmic model. For the data sets that showed $R^{2}>0.5$, the sensible heat flux $H_{\text {(grad) }}$ and deposition velocity $v_{\mathrm{d}(\mathrm{grad})}$ were calculated, with the subscript "grad" referring to the gradient pole.

\section{Results and discussion}

\subsection{Sensible heat flux estimates}

We apply the approach introduced in Sect. 4.4 to all temperature measurements by obtaining fits to the data outlined in Table 3. The first four columns summarize the measurement dates, start and sampling times, and average temperatures encountered. The next three data columns summarize the slope parameters $F_{\mathrm{h}}\left(u_{*} \kappa\right)^{-1}$, the coefficients of determination, $R^{2}$, and the friction velocity, $u_{*}$, taken from simultaneous eddy covariance measurements (Held et al., 2011). $F_{\mathrm{h}}$ and $H_{\text {(grad) }}$ were calculated only for cases when $R^{2}>0.50$; thus, the temperature gradient on 30 August was excluded.

Over the lead, the gradients strengthened as autumn freeze-up approached, indicating the removal of heat from the surface waters and ice. This was especially pronounced on 1 September, when clear skies brought 
Table 3. Summary of temperature slope parameters, kinematic sensible heat flux $F_{\mathrm{h}}$, and dynamic sensible heat flux $H$ over the lead and snow surfaces; values in parentheses are discarded due to rejection by standard errors or by low coefficients of determination $R^{2}$.

\begin{tabular}{|c|c|c|c|c|c|c|c|c|c|}
\hline date & $\begin{array}{r}\text { start } \\
\text { time } \\
\text { hh:mm }\end{array}$ & $\begin{array}{r}\text { end } \\
\text { time } \\
\text { hh:mm }\end{array}$ & $\begin{array}{l}\text { avg. } \\
\text { temp } \\
{ }^{\circ} \mathrm{C}\end{array}$ & $\begin{array}{r}F_{\mathrm{h}}\left(u_{*} \mathrm{k}\right)^{-1} \\
K\end{array}$ & $R^{2}$ & $\begin{array}{r}u_{*} \\
\mathrm{~ms}^{-1}\end{array}$ & $\begin{array}{r}F_{\mathrm{h}} \\
\mathrm{Kms}^{-1}\end{array}$ & $\begin{array}{c}H_{(\mathrm{grad})} \\
\mathrm{W} \mathrm{m}^{-2}\end{array}$ & $\begin{array}{r}H_{\text {(eddy) }} \\
\mathrm{W} \mathrm{m}^{-2}\end{array}$ \\
\hline \multicolumn{10}{|c|}{ over lead } \\
\hline $26 / 08$ & $20: 58$ & $22: 05$ & -2.1 & $3.31 \mathrm{E}-03$ & 0.81 & 0.13 & $1.72 \mathrm{E}-04$ & $0.21( \pm 0.03)$ & -0.1 \\
\hline $27 / 08 \mathrm{a}$ & $20: 46$ & $21: 14$ & -2.9 & $9.41 \mathrm{E}-03$ & 0.92 & 0.11 & 4.14E-04 & $0.51( \pm 0.18)$ & 0.04 \\
\hline $27 / 08 b$ & $21: 12$ & $21: 34$ & -1.8 & $3.62 \mathrm{E}-02$ & 1.00 & 0.08 & $1.16 \mathrm{E}-03$ & $1.4( \pm 0.2)$ & -0.04 \\
\hline $29 / 08$ & $15: 19$ & $16: 10$ & -2.6 & 5.19E-02 & 0.82 & 0.13 & $2.70 \mathrm{E}-03$ & $3.3( \pm 0.5)$ & -0.7 \\
\hline $31 / 08 \mathrm{a}$ & $10: 51$ & $12: 20$ & -4.1 & $1.07 \mathrm{E}-01$ & 0.98 & 0.17 & $7.28 \mathrm{E}-03$ & $8.9( \pm 1.0)$ & 6.7 \\
\hline $01 / 09$ & $17: 02$ & $18: 30$ & -10.7 & $1.90 \mathrm{E}-01$ & 0.94 & $0.14^{\mathrm{a}}$ & $1.06 \mathrm{E}-02$ & $13.1( \pm 1.0)$ & - \\
\hline \multicolumn{10}{|c|}{ over snow } \\
\hline $28 / 08$ & $14: 20$ & $15: 31$ & -2.4 & $1.76 \mathrm{E}-02$ & 0.94 & 0.13 & $9.15 \mathrm{E}-04$ & $1.1( \pm 0.07)$ & 0.9 \\
\hline $30 / 08$ & $11: 05$ & 13:07 & -3.9 & $(-6.96 \mathrm{E}-03)$ & 0.26 & 0.14 & - & - & -0.1 \\
\hline $31 / 08 b$ & $13: 47$ & $15: 45$ & -5.2 & $1.21 \mathrm{E}-02$ & 0.62 & 0.06 & $2.90 \mathrm{E}-04$ & $0.36( \pm 0.15)$ & 4.6 \\
\hline $26 / 08$ & $20: 58$ & $22: 05$ & -2.1 & $3.31 \mathrm{E}-03$ & 0.81 & 0.13 & $1.72 \mathrm{E}-04$ & $0.21( \pm 0.03)$ & -0.1 \\
\hline
\end{tabular}

a $u_{*}$ estimated since there were no flux data.

ambient temperatures rapidly below $-10^{\circ} \mathrm{C}$ and the measured temperature profile indicated a sensible heat flux of $13.1 \mathrm{~W} \mathrm{~m}^{-2}$.

Over the snow surface, however, weaker temperature profiles dominated. The lead/snow contrast was especially evident during measurements made on 31 August, first over the frozen lead (31/08a) and then over the snow surface (31/08b). The rather robust profile over the lead $\left(R^{2}=0.98\right)$ was followed by a close to non-detectable profile over the snow $\left(R^{2}=0.62\right)$. Over the lead, a gradient corresponding to a sensible heat flux of $H=8.9 \mathrm{~W} \mathrm{~m}^{-2}$ may be expected due to the difference between the average air temperature (in this case $-4.1^{\circ} \mathrm{C}$ ) and the average temperature of the Arctic waters of $-1.8^{\circ} \mathrm{C}$. In contrast, the snow surface covers a two to three meter thick layer of pack ice, and apart from being far more insulated from the ocean waters, has a lower thermal conductivity. The air temperature dropped from $-4.1^{\circ} \mathrm{C}$ during the lead measurements to $-5.2^{\circ} \mathrm{C}$ during the snow surface measurements, while the observed profile corresponds with a rather low sensible heat flux of $H=0.4 \mathrm{~W} \mathrm{~m}^{-2}$.

The heat flux values in this work (gradient pole 0.2 to $13.1 \mathrm{~W} \mathrm{~m}^{-2}$; eddy covariance -0.1 to $6.7 \mathrm{~W} \mathrm{~m}^{-2}$ ) fall within the range of previous measurements in Arctic summertime. Several heat flux measurements have been reported over the Arctic. For example, Persson et al. (2002) reported an average sensible heat flux between 3 and $4 \mathrm{~W} \mathrm{~m}^{-2}$ from August to September on ice floes in the Beaufort and Chukchi Seas as part of the SHEBA field experiment. They also reported $5 \mathrm{~W} \mathrm{~m}^{-2}$ as the maximum in the average diurnal sensible heat flux for the month of August. During ASCOS, the sensible heat flux showed large variability with mean values ranging from -2 to $6 \mathrm{~W} \mathrm{~m}^{-2}$ (Sedlar et al., 2010). In winter, Andreas et al. (1979) found sensible heat fluxes over Arctic leads one to two orders of magnitude larger $(\sim 100$ $500 \mathrm{~W} \mathrm{~m}^{-2}$ ) than in this summertime study.

\subsection{Particle number flux estimates}

When the approach introduced in Sect. 4.4 is applied to all particle measurements (as shown in Table 4), low coefficients of determination $R^{2}$ indicate that four concentration gradients (27/08b, 29/08, 31/08a, and 01/09) do not follow the logarithmic model. Again, this does not imply that the measurements are flawed, but the observed profiles just cannot be interpreted based on the analysis procedure outlined in Sect. 4. These gradients are discarded from further analysis. For the remaining dates, the deposition velocity $v_{\mathrm{d}(\mathrm{grad})}$ was calculated and listed in Table 4. In comparison, the temperature data in Table 3 are much more complete. This is due in-part to the stability of the temperature data, which have a background at least an order of magnitude less than the natural fluctuations present in the ambient aerosol concentrations.

In the aerosol concentration profiles, there is one particular measurement date on which the data hinge. Before $27 \mathrm{Au}-$ gust, the lead was open and not frozen. On 27 August, the lead froze and remained frozen thereafter. We were fortunate to have observed this transition during a wind shift. The data were divided into two time periods, 27/08a and 27/08b, to represent scenarios before and after freeze-up. The contrasting results through the period are seen in Table 4 , where the fitted concentration data over the lead have drastically reduced $R^{2}$ values after 27/08a. One might speculate that the formation of ice shut down the particle generation mechanism over the open lead, however, the conclusion from just 
Table 4. Summary of particle concentration slope parameters, aerosol number flux $F_{\mathrm{c}}$, and deposition velocity $v_{\mathrm{d}}$ over the lead and snow surfaces; values in parentheses are discarded due to rejection by standard errors or by low coefficients of determination $R^{2}$.

\begin{tabular}{|c|c|c|c|c|c|c|c|c|c|}
\hline date & $\begin{array}{r}\text { start } \\
\text { time } \\
\text { hh:mm }\end{array}$ & $\begin{array}{r}\text { end } \\
\text { time } \\
\text { hh:mm }\end{array}$ & $\begin{array}{c}\text { avg. } \\
\text { conc. } \\
\mathrm{cm}^{-3}\end{array}$ & $\begin{array}{c}F_{\mathrm{c}}\left(u_{*} \mathrm{k}\right)^{-1} \\
\mathrm{~cm}^{-3}\end{array}$ & $R^{2}$ & $\begin{array}{r}u_{*} \\
\mathrm{~m} \mathrm{~s}^{-1}\end{array}$ & $\begin{array}{r}F_{\mathrm{c}} \\
\mathrm{m}^{-2} \mathrm{~s}^{-1}\end{array}$ & $\begin{array}{l}v_{\mathrm{d}(\mathrm{grad})} \\
\mathrm{mm} \mathrm{s}^{-1}\end{array}$ & $\begin{array}{l}v_{\mathrm{d}(\text { eddy })} \\
\mathrm{mm} \mathrm{s}^{-1}\end{array}$ \\
\hline \multicolumn{10}{|c|}{ over lead } \\
\hline $26 / 08$ & $20: 58$ & $22: 05$ & 71.2 & $1.07 \mathrm{E}-01$ & 0.62 & 0.13 & $5.56 \mathrm{E} 03$ & $-0.08( \pm 0.01)$ & $-0.09( \pm 0.1)$ \\
\hline $27 / 08 \mathrm{a}$ & $20: 46$ & $21: 14$ & 55.3 & $1.29 \mathrm{E}+00$ & 0.79 & 0.11 & $5.68 \mathrm{E} 04$ & $-1.0( \pm 0.1)$ & $-0.44( \pm 0.1)$ \\
\hline $27 / 08 b$ & $21: 12$ & $21: 34$ & 42.5 & $(2.35 \mathrm{E}-02)$ & 0.01 & 0.08 & - & - & $-0.05( \pm 0.1)$ \\
\hline $29 / 08$ & $15: 19$ & $16: 10$ & 56.7 & $(-4.76 \mathrm{E}-02)$ & 0.16 & 0.13 & - & - & $0.0( \pm 0.1)$ \\
\hline $31 / 08 \mathrm{a}$ & $10: 51$ & $12: 20$ & 8.6 & $(1.90 \mathrm{E}-03)$ & 0.01 & 0.17 & - & - & $0.35( \pm 0.6)$ \\
\hline $01 / 09$ & $17: 02$ & $18: 30$ & 7.9 & $(-6.50 \mathrm{E}-03)$ & 0.14 & $0.14^{\mathrm{a}}$ & - & - & - \\
\hline \multicolumn{10}{|c|}{ over snow } \\
\hline $24 / 08$ & $14: 23$ & $14: 41$ & 72.4 & $-9.74 \mathrm{E}-01$ & 0.77 & 0.24 & $-9.35 \mathrm{E} 04$ & $1.3( \pm 0.2)$ & - \\
\hline $28 / 08$ & $14: 20$ & $15: 31$ & 61.9 & $-4.54 \mathrm{E}-01$ & 0.98 & 0.13 & $-2.36 \mathrm{E} 04$ & $0.38( \pm 0.06)$ & $0.58( \pm 0.2)$ \\
\hline $30 / 08$ & 11:05 & 13:07 & 22.3 & $-7.12 \mathrm{E}-02$ & 0.75 & 0.14 & $-3.99 \mathrm{E} 03$ & $0.18( \pm 0.03)$ & $-8.02( \pm 0.2)$ \\
\hline $31 / 08 b$ & $13: 47$ & $15: 45$ & 8.51 & 4.73E-02 & 0.73 & 0.06 & $1.14 \mathrm{E} 03$ & $-0.13( \pm 0.02)$ & $0.28( \pm 0.4)$ \\
\hline
\end{tabular}

a $u_{*}$ estimated since there were no flux data.

one measurement would be unreliable. Also important to consider are the lower ambient particle number concentrations (less than $60 \mathrm{~cm}^{-3}$ ) measured after the transition on 27 August which made surface sinks harder to detect. In contrast, the detection of weak surface sources would be aided by the low ambient concentrations but were not observed either.

For the strongest source profile on 27 August (27/08a), the calculated particle number flux is $F_{\mathrm{c}}=5.68 \times 10^{4}$ particles $\mathrm{m}^{-2} \mathrm{~s}^{-1}$. Converting units this corresponds with a net emission of approximately 340 particles $\mathrm{cm}^{-2} \mathrm{~min}^{-1}$. If we assume a $100 \mathrm{~m}$ mixing depth, a reasonable height for the central Arctic boundary layer (Tjernström, 2005), and a $15 \mathrm{~min}$ residence time of an air parcel over open water, then the net change in particle concentration would be approximately 0.5 particles $\mathrm{cm}^{-3} \mathrm{~h}^{-1}$, without considering sink mechanisms.

If we compare this number to the range of variability in particle number concentrations that were observed, it will give us an idea of how the source might impact the aerosol population. We estimate from the CPC observations that the particle variability ranged from 20 to $100 \mathrm{~cm}^{-3} \mathrm{~h}^{-1}$ for ambient particle concentrations between 0.1 and $100 \mathrm{~cm}^{-3}$. Therefore, an aerosol source on the order of $0.5 \mathrm{~cm}^{-3} \mathrm{~h}^{-1}$ might only be observed under stable conditions with low particle concentrations; in most other cases, it may be considered negligible.

Particle profiles over the snow covered ice surface showed a different behavior. On 24, 28, and 30 August, the results imply an aerosol sink at the surface. One inconsistent profile occurred on 31 August (31/08b), where the trend was opposite and implied a weak source. The values of the calcu- lated deposition velocities are in good agreement with previous measurements of particle number fluxes over snow surfaces and in the Arctic. Duan et al. (1988) report values of $v_{\mathrm{d}}=0.34 \mathrm{~mm} \mathrm{~s}^{-1}$ over snow for particles in the size range from 0.15 to $0.3 \mu \mathrm{m}$. Bergin et al. (1995) derived deposition velocities of particulate sulfate ranging from $v_{\mathrm{d}}=0.23$ to $0.62 \mathrm{~mm} \mathrm{~s}^{-1}$ using surrogate surfaces and impactor data. Grönlund et al. (2002) found slightly higher transfer velocities of 0.8 to $18.9 \mathrm{~mm} \mathrm{~s}^{-1}$ using a condensation particle counter and eddy covariance over snow. In the high Arctic, Nilsson and Rannik (2001) report median deposition velocities $v_{\mathrm{d}}=0.26 \mathrm{~mm} \mathrm{~s}^{-1}$ over ice and $v_{\mathrm{d}}=0.40$ to $0.73 \mathrm{~mm} \mathrm{~s}^{-1}$ towards open leads. They also observed emission fluxes on the same order of magnitude. During ASCOS, Held et al. (2011) observed particle deposition values ranging from 0.27 to $0.68 \mathrm{~mm} \mathrm{~s}^{-1}$ during deposition-dominated periods.

\subsection{Intercomparison with eddy covariance measurements}

Finally, the flux estimates calculated from the gradient pole are compared with direct eddy covariance flux measurements by Held et al. (2011).

The sensible heat fluxes measured directly by eddy covariance $\left(H_{\text {eddy }}\right)$ during the deployment of the gradient pole are summarized in Table 3 for comparison against the profile data. It appears that the best agreement occurs on 31/08a and 28/08, when the gradient pole also shows good $R^{2}$ values. Obviously, the disagreement between $H_{\text {grad }}$ and $H_{\text {eddy }}$ dominates. It is important to keep in mind that the fluxes are derived indirectly from the gradient pole data assuming that turbulence is developed. It is interesting to note that the $R^{2}$ 
values for the gradient pole data are fairly good for nearly all profiles (with the exception of 30/08), and apart from any fitting, the existence of temperature gradients is evident in the raw gradient pole data, as shown for example in Fig. 3. It must be kept in mind that the eddy covariance flux derived from the sonic temperature fluctuations is not the sensible heat flux but close to the buoyancy flux. However, Andreas et al. (2005) demonstrated that for typical polar conditions (low temperature, and hence low absolute humidity) the sonic temperature flux is a very good approximation to the sensible heat flux. It should also be noted that the eddy covariance system was located approximately $300 \mathrm{~m}$ from the gradient pole, and although we designed the experiments in a way that the air trajectories from over the lead or the snow surface were the same for both systems, it is certain that the actual surface footprint was different for the two measurements. This could also be due to the height difference between the two measurements: the eddy covariance system located at $2.5 \mathrm{~m}$ above ground could reasonably be decoupled from the $1.5 \mathrm{~m}$ surface layer in which the gradient pole was deployed. Rapid changes in the magnitude and direction of the flux, for example, could localize the measurements, producing converging and diverging flux profiles with height. However, turbulence measurements at various heights during ASCOS do not provide evidence for decoupled layers.

Nevertheless, we also compare the particle deposition velocities, $v_{\mathrm{d}(\mathrm{grad})}$ and $v_{\mathrm{d}(\mathrm{eddy})}$, in Table 4 . There are two particle source cases over the lead before freeze-up, and two sink cases over the snow covered ice surface (24/08 and 28/08) that show good agreement. The low $R^{2}$ value on $24 \mathrm{Au}-$ gust is likely due to the low number of data points since only two profiles were measured with the gradient pole. For the transitional day when the lead froze on 27 August, $v_{\mathrm{d}(\text { (eddy) }}$ also indicates a transition in the same direction as data collected with the gradient pole. A change in $v_{\mathrm{d}(\text { eddy) }}$ from $-0.44 \mathrm{~mm} \mathrm{~s}^{-1}$ to $-0.05 \mathrm{~mm} \mathrm{~s}^{-1}$ is consistent with the shutdown of a particle source at the lead, indicated by a change in $v_{\mathrm{d}(\mathrm{grad})}$ from $-1.0 \mathrm{~mm} \mathrm{~s}^{-1}$ to a situation without any detectable profile.

In order to visualize these results, we construct profiles corresponding with the eddy covariance data and compare them directly against the profiles measured with the gradient pole. In Fig. 8a, we continue with the case shown in Fig. 7a (31/08a). First, we use the slope calculated from the gradient pole data in Fig. 7a, and extend the logarithmic curve from the temperature measured at the lowest height. The uncertainty shown is the standard deviation determined for each data point. As one would expect for a good $R^{2}$ value, the reconstructed profile (grey line) passes fairly well through the data points. The black curve in Fig. 8a is the profile derived from the eddy covariance flux measurement extrapolated down to the same reference temperature at surface level. The error bars indicate the estimated uncertainties in the sensible heat flux, taken as $20 \%$ in the eddy covariance measurements (Foken, 2008). The constructed eddy covariance profile is consistent with a sensible heat flux of $6.7 \mathrm{~W} \mathrm{~m}^{-2}$ which is slightly smaller but on the same order as the gradient measurement of $8.9 \mathrm{~W} \mathrm{~m}^{-2}$, and within the estimated uncertainties of the flux values.

For the aerosol concentration profiles, we extend the example of 28 August in Fig. 8b and compare the aerosol profile from the gradient data with the profile consistent with the eddy covariance measurements. The uncertainty of the reconstructed profile (grey line) is the standard deviation determined for each data point. The two profiles seen in Fig. 8b can be considered in reasonable agreement, however with a large uncertainty. In this case, the deposition velocity from the gradient measurements $v_{\mathrm{d}(\mathrm{grad})}=0.38 \mathrm{~mm} \mathrm{~s}^{-1}$ is compared against $v_{\mathrm{d}(\text { eddy })}=0.58 \mathrm{~mm} \mathrm{~s}^{-1}$. The agreement between the two curves appears reasonable and just contained within the uncertainty of the eddy covariance measurement due to particle counting statistics indicated by the error bars of the black curve. The uncertainty of the deposition velocity $\Delta v_{\mathrm{d}}$ was calculated after Fairall (1984) by

$\Delta v_{\mathrm{d}}=\frac{\sigma_{w}}{\sqrt{N}}$,

where $\sigma_{w}$ is the standard deviation of the vertical wind speed, and $N$ is the total number of particles counted during the averaging interval of $30 \mathrm{~min}$.

\section{Conclusions}

A gradient pole was deployed over the Arctic pack ice area at about $87^{\circ} \mathrm{N}$ to measure temperature and particle number concentration profiles in height steps varying from $1-2 \mathrm{~cm}$ up to $1.5 \mathrm{~m}$ above the surface. Nearby, a sonic anemometer and particle counter at a height of $2.5 \mathrm{~m}$ were used to directly measure the sensible heat and particle number fluxes by eddy covariance. The results were compared over the snow covered pack ice, and over the open and frozen lead. In the time period of deployment (24 August to 1 September), the open lead froze, ambient temperatures dropped, and particle number concentrations decreased from around $100 \mathrm{~cm}^{-3}$ to below $10 \mathrm{~cm}^{-3}$.

The sensible heat flux and particle deposition velocity were calculated from the gradient pole data by applying a linear regression to the data assuming it followed a logarithmic profile. The logarithmic behavior of the data was confirmed for all cases where an obvious trend was seen, as indicated by the $R^{2}$ values.

In nearly all cases, the ambient temperatures measured with the gradient pole increased towards the surface, giving positive heat flux values. The strongest temperature gradients were measured after the open lead froze on 27 August. The corresponding sensible heat fluxes reached maximum values of 8.9 and $13.1 \mathrm{~W} \mathrm{~m}^{-2}$ over the lead.

Before freeze-up, an enhanced number of aerosol particles just above the open lead surface revealed weak particle 

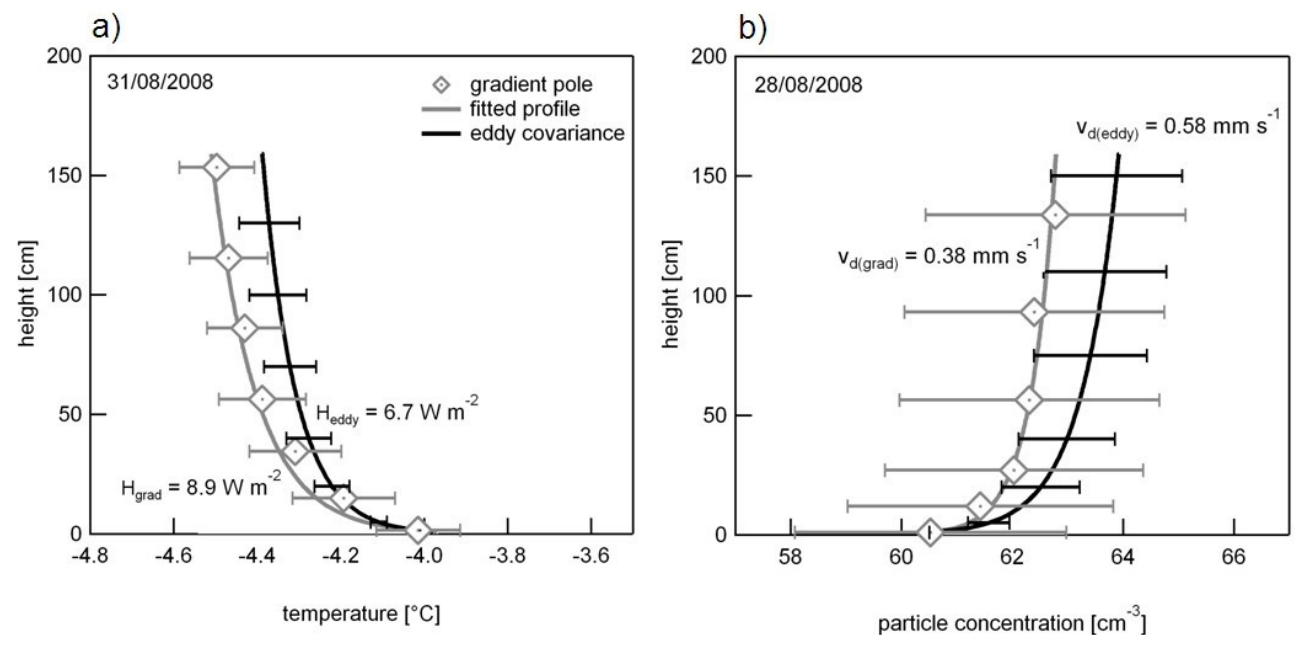

Fig. 8. Intercomparison of profiles fitted to the gradient pole data (grey) and profiles consistent with the simultaneous eddy covariance flux measurement (black). (a) Temperature profiles on 31 August, and (b) particle concentration profiles on 28 August.

emission in two measurements over the open lead which was confirmed by eddy covariance measurements. No reliable particle number profiles of any sort were detected over the frozen lead. The snow surfaces behaved in general as particle sinks with deposition velocities ranging from 0.18 to $1.3 \mathrm{~mm} \mathrm{~s}^{-1}$ by the gradient method, and ranging from 0.28 to $0.58 \mathrm{~mm} \mathrm{~s}^{-1}$ by eddy covariance. These findings corroborate the original hypothesis that open leads can act as particle sources.

An operational shortcoming of the gradient pole as presented in this study lies in the manual control of heights and timing. Therefore, the data collection can only be a snapshot representation of the atmospheric conditions, in contrast to continuous monitoring with the eddy covariance system. However, its simplicity in construction and profile acquisition might offer advantages, for example as an alternative to more expensive and complicated eddy covariance systems. Also, the capability to carry out measurements very close to the surface is beneficial.

Although the gradient pole method is an indirect way to calculate the flux, it appeared to reveal strong gradients even when the eddy covariance data were ambiguous. This was already observed in the raw data. However, it has to be kept in mind that the estimated flux values presented in this study rely on the knowledge of $u_{*}$ from an independent measurement (with a flux footprint different from the gradient pole footprint). A reliable estimate of the friction velocity is always required. Without turbulence measurements, $u_{*}$ may be parameterized using a wind speed measurement while estimating the surface roughness. With wind speed measurements at two or more heights, the friction velocity and the roughness can (in theory) be estimated directly.
Finally, the gradient pole method may be extended by adding, for example, a fast scanning mobility particle sizer for size-resolved particle measurements, a humidity sensor, or aerosol and trace gas analyzers. Further improvements such as an integrated data acquisition system and a fully automated inlet height control will make the presented setup even more practical in future studies.

Acknowledgements. This work is part of ASCOS (the Arctic Summer Cloud-Ocean Study) and was funded by the German Research Foundation No. HE939/29-1. AH was supported by the Bert Bolin Center for Climate Research at Stockholm University. PV was supported by the Finnish Cultural Foundation, Lapland Regional fund. ASCOS was made possible by funding from the Knut and Alice Wallenberg Foundation, the Swedish Research Council and the DAMOCLES European Union 6th Framework Integrated Research Project. The Swedish Polar Research Secretariat (SPRS) provided access to the icebreaker Oden and logistical support. We are grateful to the Swedish Polar Research Secretariat logistics staff and to Oden's captain Mattias Peterson and his crew. ASCOS is an IPY project under the AICI-IPY umbrella and is an endorsed SOLAS project. Thanks are due to Jost Heintzenberg and David Covert for an endless exchange of ideas.

Edited by: I. Brooks

\section{References}

Aller, J. Y., Kuznetsova, M. R., Jahns, C. J., and Kemp, P. F.: The sea surface microlayer as a source of viral and bacterial enrichment in marine aerosols, J. Aerosol Sci., 36, 801-812, 2005.

Andreas, E. L: Comment on "Vertical coarse aerosol fluxes in the atmospheric surface layer over the North Polar Waters of the Atlantic" by Tomasz Petelski and Jacek Piskozub, J. Geophys. Res., 112, C11010, doi:10.1029/2007JC004184, 2007. 
Andreas, E. L., Paulson, C. A., Williams, R. M., Lindsay, R. W., and Businger, J. A.: The turbulent heat flux from Arctic leads, Bound. Lay. Meteorol., 17, 57-91, 1979.

Andreas, E. L., Paulson, C. A., and Williams, R. M.: Observations of condensate profiles over Arctic leads with a hot-film anemometer, Q. J. Roy. Meteorol. Soc., 107, 437-460, 1981.

Andreas, E. L., Jordan, R. E., and Makshtas, A. P.: Parameterizing turbulent exchange over sea ice: The ice station Weddell results, Bound. Lay. Meteorol., 114, 439-460, 2005.

Andreas, E. L., Jones, K. F., and Fairall C. W.: Production velocity of sea spray droplets, J. Geophys. Res., 115, C12065, doi:10.1029/2010JC006458, 2010.

Bergin, M. H., Jaffrezo, J.-L., Davidson, C. I., Dibb, J. E., Pandis, S. N., Hillamo, R., Maenhaut, W., Kuhns, H. D., and Makela, T.: The contributions of snow, fog, and dry deposition to the summer flux of anions and cations at Summit, Greenland, J. Geophys. Res., 100, 16275-16288, 1995.

Bezdek, H. F. and Carlucci, A. F.: Concentration and removal of liquid microlayers from a seawater surface by bursting bubbles, Limnol. Oceanogr., 19, 126-132, 1974.

Bigg, E. K. and Leck, C.: The composition of fragments of bubbles bursting at the ocean surface, J. Geophys. Res., 113(D1), 1209, doi:10.1029/2007JD009078, 2008.

Bigg, E. K., Leck, C., and Tranvik, L.: Particulates of the surface microlayer of open water in the central Arctic Ocean in summer, Mar. Chem., 91, 131-141, 2004.

Blanchard, D. C.: Electrically charged drops from bubbles in sea water and their meteorological significance, J. Atmos. Sci., 15, 383-396, 1958.

Businger, J. A.: A note on the Businger-Dyer profiles, Bound. Lay. Meteorol., 42, 145-151, 1988.

Ceburnis, D., O’Dowd, C. D., Jennings, G. S., Facchini, M. C., Emblico, L., Decesari, S., Fuzzi, S., and Sakalys, J.: Marine aerosol chemistry gradients: Elucidating primary and secondary processes and fluxes, Geophys. Res. Lett., 35, L07804, doi:10.1029/2008GL033462, 2008.

Chin, W. C., Orellana, M. V., and Verdugo, P.: Spontaneous assembly of marine dissolved organic matter into polymer gels, Nature, 391, 568-572, 1998.

Covert, D. S., Wiedensohler, A., Aalto, P., Heintzenberg, J., McMurry, P. H., and Leck, C.: Aerosol number size distributions from 3 to $500 \mathrm{~nm}$ diameter in the arctic marine boundary layer during summer and autumn, Tellus B, 48, 197-212, 1996.

Duan, B., Fairall, C. W., and Thomson, D. W.: Eddy correlation measurements of the dry deposition of particles in wintertime, J. Appl. Meteorol., 27, 642-652, 1988.

Dyer, A. J.: A review of flux-profile relationships, Bound. Lay. Meteorol., 7, 363-372, 1974.

Fairall, C. W.: Interpretation of eddy-correlation measurements of particulate deposition and aerosol flux, Atmos. Environ., 18, 1329-1337, 1984.

Fairall, C. W., Banner, M. L., Pierson, W. L., Asher, W., and Morison, R. P.: Investigation of the physical scaling of sea spray spume droplet production, J. Geophys. Res., 114, C10001, doi:10.1029/2008JC004918, 2009.

Foken, T.: Micrometeorology, Springer, Berlin, 306 pp., 2008.

Grönlund A., Nilsson, D., Koponen, I. K., Virkkula, A., and Hansson, M.: Aerosol dry deposition measured with eddy-covariance technique at Wasa and Aboa, Dronning Maud Land, Antarctica,
Ann. Glaciol., 35A, 355-361, 2002.

Held, A., Brooks, I. M., Leck, C., and Tjernström, M.: On the potential contribution of open lead particle emissions to the central Arctic aerosol concentration, Atmos. Chem. Phys., 11, 30933105, doi:10.5194/acp-11-3093-2011, 2011.

Horst, T. W.: A simple formula for attenuation of eddy fluxes measured with first-order-response scalar sensors, Bound. Lay. Meteorol., 82, 219-233, 1997.

Kaimal, J. C. and Finnigan, J. J.: Atmospheric boundary layer flows, Oxford University Press, New York, Oxford, 289 pp., 1994.

Kuznetsova, M., Lee, C., and Aller, J.: Characterization of the proteinaceous matter in marine aerosols, Mar. Chem., 96, 359-377, 2005.

Lanzante, J. R.: A cautionary note on the use of error bars, J. Climate, 18, 3699-3703, 2005.

Leck, C. and Bigg, E. K.: Aerosol production over remote marine areas - a new route, Geophys. Res. Lett., 26, 3577-3580, 1999.

Leck, C. and Bigg, E. K.: Biogenic particles in the surface microlayer and overlaying atmosphere in the central Artic ocean during summer, Tellus, 57B, 305-316, 2005a.

Leck, C. and Bigg, E. K.: Source and evolution of the marine aerosol - a new perspective, Geophys. Res. Lett., 32, L19803, doi:10.1029/2005GL023651, 2005b.

Leck, C. and Bigg, E. K.: A modified aerosol-cloudclimate feedback hypothesis, Environ. Chem., 4, 400-403, doi:10.1071/EN07061, 2007.

Leck, C. and Bigg, E. K.: Comparison of sources and nature of the tropical aerosol with the summer high Arctic aerosol, Tellus, 60B, 118-126, doi:10.1111/j.1600-0889.2007.00315.x, 2008.

Leck, C. and Bigg, E. K.: New particle formation of marine biological origin, Aerosol Sci. Technol., 44, 570-577, 2010.

Leck, C., Norman, M., Bigg, E. K., and Hillamo, R.: Chemical composition and sources of the high Arctic aerosol relevant for fog and cloud formation, J. Geophys. Res., 107(D12), 4135, doi:10.1029/2001JD001463, 2002.

Nilsson, E. D. and Rannik, Ü.: Turbulent aerosol fluxes over the Arctic Ocean: 1. Dry deposition over sea and pack ice, J. Geophys. Res., 106, 32125-32137, 2001.

Norris, S. J., Brooks, I. M., de Leeuw, G., Sirevaag, A., Leck, C., Brooks, B. J., Birch, C. E., and Tjernström, M.: Measurements of bubble size spectra within leads in the Arctic summer pack ice, Ocean Sci., 7, 129-139, doi:10.5194/os-7-129-2011, 2011.

Persson, P. O. G., Fairall, C. W., Andreas, E. L, Guest, P. S., and Perovich, D. K.: Measurements near the Atmospheric Surface Flux Group tower at SHEBA: Near-surface conditions and surface energy budget, J. Geophys. Res., 107(C10), 8045, doi:10.1029/2000JC000705, 2002.

Petelski, T.: Marine aerosol fluxes over open sea calculated from vertical concentration gradients, J. Aerosol Sci., 34, 359-371, 2003.

Petelski, T. and Piskozub, J.: Vertical coarse aerosol fluxes in the atmospheric surface layer over the North polar waters of the Atlantic, J. Geophy. Res., 111, C06039, doi:10.1029/2005JC003295, 2006.

Petelski, T. and Piskozub, J.: Reply to comment by Edgar L Andreas on "Vertical coarse aerosol fluxes in the atmospheric surface layer over the North Polar Waters of the Atlantic", J. Geophys. Res., 112, C11011, doi:10.1029/2007JC004399, 2007. 
Scott, W. D. and Levin, Z.: Open channels in sea ice (leads) as ion sources, Science, 177, 425-426, 1972.

Sedlar, J., Tjernström, M., Mauritsen, T., Shupe, M. D., Brooks, I. M., Persson, P. O. G., Birch, C. E., Leck, C. Sirevaag, A., and Nicolaus, M.: A transitioning Arctic surface energy budget: the impacts of solar zenith angle, surface albedo and cloud radiative forcing, Clim. Dynam., online first, doi:10.1007/s00382010-0937-5, 2010.

Tjernström, M.: The summer Arctic boundary layer during the Arctic Ocean Experiment 2001 (AOE-2001), Bound. Lay. Meteorol., 117, 5-36, 2005.
Wilczak, J. M., Oncley, S. P., and Stage, S. A.: Sonic anemometer tilt correction algorithms, Bound. Lay. Meteorol., 99, 127-150, 2001.

Wyers, G. P. and Duyzer, J. H.: Micrometeorological measurement of the dry deposition flux of sulphate and nitrate aerosols to coniferous forest, Atmos. Environ., 31, 333-343, 1997. 